\title{
ARTICLE
}

\section{A Rapid Implementation of a Reserve Reading List Solution in Response to the COVID-19 Pandemic}

Matthew Black and Susan Powelson

\section{ABSTRACT}

In the spring of 2020, as post-secondary institutions and libraries were adapting to the COVID-19 pandemic, Libraries and Cultural Resources at the University of Calgary rapidly implemented Ex Libris' reading list solution Leganto to support the necessary move to online teaching and learning. This article describes the rapid implementation process and changes to our reserve reading list service and policies, reviews the status of the implementation to date and presents key takeaways which will be helpful for other libraries considering implementing an online reading list management system or other systems on a rapid timeline. Overall, rapid implementation allowed us to meet our immediate need to support online teaching and learning; however, long term successful adoption of this tool will require additional configuration, engagement, and support.

\section{INTRODUCTION}

In response to the changes to the post-secondary learning environment due to COVID-19 and to better integrate our course reserve reading list services with our library management system (Ex Libris' Alma), Libraries and Cultural Resources (LCR) at the University of Calgary (UCalgary) decided to rapidly implement Ex Libris' reading list solution Leganto. After rapidly implementing this reading list solution, LCR made it accessible to instructors and students in our learning management system, Desire2Learn (D2L), for the fall 2020 term. This article will discuss LCR's decision to rapidly implement Leganto, the implementation process, changes to our reserve reading list service and policies, and will conclude by reviewing the implementation so far and present key takeaways. This paper will be helpful for those who are considering implementing an online reading list management system in general but more so for those looking to do so on a rapid timeline. It will also be helpful for those implementing new systems to support changes to services due to COVID-19.

\section{LITERATURE REVIEW}

Online reading lists management systems have been in use since the early 2000s. From 1999 to 2000, Loughborough University developed and implemented an in-house open-source reading list management system which "was an electronic representation of the academic's paper-based reading list." 1 Since then open-source and commercial solutions have been developed and implemented by many libraries. Richard Cross summarizes the development and growth of the market for "resource list software" in the UK and notes that "in the absence of a mature commercial market, several UK universities have developed in-house" systems. Cross notes that since 2010, commercial solutions have been developed and that "the high-level specifications requirements" for reading list management systems have now been distilled. ${ }^{2}$ As part of the development of the commercial market, Ex Libris launched its Leganto online reading list solution in 2015; the solution has since been implemented by over 230 institutions worldwide. $^{3}$

Matthew Black (mblack@ucalgary.ca) is the Discovery \& Systems Librarian, University of Calgary. Susan Powelson (spowelso@ucalgary.ca) is the Associate University Librarian, Technology, Discovery \& Digital Services, University of Calgary. (C) 2021. 
Overall, the literature on reading list management systems focuses on reviewing implementations and identifying factors that contribute to successful implementation of these solutions. ${ }^{4} \mathrm{Also}$, some literature captures instructor and student perceptions of these systems and provides recommendations for successful engagement and use. ${ }^{5}$ These recommendations focus on the importance of administrative support for the tool, updating or creating policy and workflows to support implementation, technical configurations and integrations, and faculty/instructor engagement. ${ }^{6}$

Libraries that have implemented an online reading list system indicate that it is important to have the adoption of the system supported and championed by senior administration within the library and from the wider institution. ${ }^{7}$ Having this support means that reading list policies and services can be aligned with library and institutional goals to support teaching and learning. Furthermore, Marie $\mathrm{O}^{\prime} \mathrm{Neill}$ and Lara Musto contend that successful adoption is dependent on this support and integration with institutional goals and not just "premised on technology."

Establishing policies and service goals that are supported by senior administration provides an impetus to make sure workflows and functionalities are configured to achieve these. The literature recommends that implementing an online reading list solution provides an important opportunity to review or revise previous workflows or to develop new workflows for standardization and "timely satisfaction of resource list needs."

To support these new workflows and services, technical integrations and configurations need to be considered. These include integrations with the library management system, the learning management system (LMS), and institutional authentication systems. ${ }^{10}$ These integrations are essential to make the system streamlined and accessible for instructors and students and are expected by these user groups. For example, when the University of Manchester Library was implementing Leganto in 2019, they surveyed students and instructors and found that students valued convenience and access, and that instructors were interested in a system that would allow them to order books and digitized chapters and see analytics. ${ }^{11}$ Thus, the reading list solution should be configured and implemented with functionalities and integrations to support these expectations.

Ease of access within the LMS is perceived as is an important technical requirement for successful implementation. O'Neill and Musto's study finds that faculty had a strong desire to have a reading list system integrated with the LMS. ${ }^{12}$ Meredith Gorran Farkas contends that "positioning the library at the heart of the virtual campus seems as important as positioning the library as the heart of the physical campus. ${ }^{13}$ Murray and Feinberg address the placement of LibGuides in the learning management system stating it is critical to make resources available despite where students are physically located." ${ }^{14}$ This can be extrapolated to reading lists, and in this environment, where students are learning online in geographically dispersed locations, the lists need to be easily available.

Faculty and student engagement are important nontechnical considerations when embedding library services in the LMS. Knowing and including relevant stakeholders, gaining instructor buyin and understanding of the benefits, and determining how to raise student awareness of the tool, both short and longer term, are key elements. ${ }^{15}$ The literature recommends providing instructors with resources such as templates and training "at specific points in the semesters when faculty have less time pressures." ${ }^{16}$ However, engagement should not be limited to this: it should be 
ongoing and collaborative. This ongoing engagement can work to create "a virtuous circle" in which instructors "see return on the investment in resource list work" and "improved student satisfaction." ${ }^{17}$ One university reports this can provide an opportunity for collaboration and generate "word-of mouth" to promote adoption. ${ }^{18}$

\section{WHAT IS LEGANTO?}

Leganto is a cloud-based reading list solution fully integrated with Ex Libris' Alma library management system. It allows reading lists to be processed directly in Alma by library staff and provides an interface for creating and engaging with readings lists that can be integrated directly into learning management systems using the Learning Tools Interoperability (LTI) integration. Instructors can use Leganto to create reading lists by searching for and adding resources. Leganto allows diverse resources to be added to reading lists, including physical and electronic resources that are in Alma, Ex Libris discovery index resources (via their Central Discovery Index), internet sources (any URL added manually or through the Cite It! browser bookmark tool), or uploaded resources (documents uploaded by the instructor).

\section{UNIVERSITY OF CALGARY CONTEXT}

The University of Calgary is a comprehensive research university, ranked one of Canada's top ten research universities. ${ }^{19}$ The University is home to 14 faculties (offering more than 200 academic programs) and more than 33,000 students are currently enrolled in undergraduate, graduate, and professional degree programs. D2L is the university's learning management system, managed by the university's teaching and learning unit. Libraries and Cultural Resources is a principal division of the University of Calgary and includes eight libraries on campus and across the city, and two art galleries. The main library is the Taylor Family Digital Library (TFDL) which opened in 2011. In 2018, LCR adopted Ex Libris' Alma as its library management system.

\section{Pre-COVID-19 Reserve Reading List Service}

Prior to COVID-19, LCR had distinct and unintegrated systems and processes for managing course reserves and reading lists. While some functions in Alma were used to manage physical course reserves, most of the workflows were managed outside of Alma. These included a web form that instructors could use to submit requests for course materials and a course reserve tool (Atlas Systems' Ares product). The submissions from the web form would be reviewed by our Copyright Office who would determine if the requested item needed copyright clearance or not. Through this process, physical items which were already in the library collection were flagged and sent to Fulfillment staff. Staff would create or update the course in Alma, add the item to a course reading list, and move it to a reserve location so it could be borrowed by students. Doing this also made the items searchable through our course reserve search in our discovery service (Primo). Requested items that were not in the library collection were sent to the Collections department for purchase consideration. Through email communications with the Copyright Office, instructors could also request parts of items be scanned and approved for use in classes. Requests for electronic reserves were not managed in Alma.

\section{How did COVID-19 affect our reserve reading list service?}

Shortly after the COVID-19 pandemic became widespread in the province of Alberta, the government implemented restrictions which required post-secondary institutions to close physical locations and to restrict or move most courses and services online. In March 2020, LCR had to close all physical locations and was only able to provide online access to resources and 
services. From March to August, LCR focused on online services and promoted access to online resources. The main Taylor Family Digital Library was not able to open until August, when we began offering contactless pickup service and limited study space bookings.

As of July 2021, the majority of the courses offered by the university continue to be online. As a result, we are not fulfilling instructor requests to make print/physical resources accessible to students through course reserve. This has been a significant change from our previous operations in which physical course reserve was a popular and successful service. In 2019, LCR had a total 3,428 physical items added in Alma as course reserve citations and these items circulated 16,345 times.

With the announcement that fall 2020 term courses would be predominantly online, and the anticipation that the same would hold true for winter 2021, we realized that a new mechanism to deliver course reserves would be necessary. While we had been considering Ex Libris' course reading list tool before the pandemic, the operational changes due to COVID-19 provided us with an urgent need and impetus. We had to quickly develop alternative ways to support instructors in creating reading lists and for students to access reading list resources in the online learning environment.

\section{LEGANTO RAPID IMPLEMENTATION}

Leganto implementation is managed by Ex Libris and is typically done over an eight-to-twelveweek schedule. During this implementation, institutions work with Ex Libris to set up configurations to meet local needs. In 2020, Ex Libris began offering rapid implementation for Leganto, which involves a shortened timeline of approximately four to five weeks. This is achievable because institutions allow Ex Libris staff to set up the Leganto Now configuration, which focuses on configuring essential features to quickly get the tool up and running.

There are inherent tradeoffs between the typical and rapid implementation that we needed to consider. The shortened timeline would allow us to launch the service sooner and begin promoting it as a tool to support faculty in moving to teaching online due to COVID-19. In addition, because we would implement Leganto out of the box we could use the vendor created videos and support tools rather than creating our own. The additional three to seven weeks required for the typical implementation would have provided us more time to fine tune and configure the tool to meet our specific needs but would have delayed our ability to support our faculty in this time of need. For example, the rapid implementation schedule did not include support for setting up workflows for digitization requests or configuration of the more advanced copyright clearance functions to improve automatic processing. To configure these, we would need to work on them on our own while going through the rapid implementation or once the implementation was complete.

After considering these tradeoffs, in April 2020 we made the decision to rapidly implement Leganto. This decision was supported by the Provost and LCR senior administration providing us with the institutional support identified in the literature as necessary for a successful implementation. Table 1 outlines the rapid implementation schedule we followed. 
Table 1. Project implementation schedule

\begin{tabular}{|l|l|}
\hline Event & Dates \\
\hline Kickoff & May 27, 2020 \\
\hline Implementation & May 28 to June 28, 2020 \\
\hline Go-live & June 29, 2020 \\
\hline Switch to support & July 15, 2020 \\
\hline
\end{tabular}

The implementation portion involved weekly meetings to review the project status, frequent posting to the online project management tool to update the status and ask clarifying questions, and many internal meetings to discuss our progress and to make decisions about workflows, configurations, and engagement. As a requirement for go-live, at least one reading list had to be created by an instructor and be accessible to students. Ex Libris offered the opportunity to implement together with the University of Manitoba, which is a similarly sized Canadian university. This was a great opportunity to not only start implementation sooner but also connect with the University of Manitoba.

In the short term, rapid implementation would help us meet an immediate need to support online access and learning while operating under COVID-19 restrictions. In the long term, this was an opportunity to develop a new way to engage with instructors and further promote our collections as resources for supporting learning. Also, it was the opportunity to revise or develop workflows to support these goals. Overall, we hoped Leganto would make it easier for instructors to add resources to reading lists and to get copyright clearance so these resources would be accessible to students through a standardized tool integrated with D2L. With these goals in mind, we aimed to

- pilot Leganto for summer 2020 term,

- have Leganto accessible for all courses by fall 2020 term, and

- revise or develop workflows for digitization, copyright clearance, and purchase requests.

\section{Implementation work}

Despite the out-of-the-box Leganto Now configuration which aimed to have Leganto up and running for our go-live date, implementation still required the LCR team to do a significant amount of work and planning. To manage this work, we established a technical team and an engagement team. The technical team, comprised of representatives from the library's Systems and Discovery, Copyright, Digitization and Collections units, the university's Teaching and Learning unit, and the Associate University Librarian, Technology, Discovery and Digital Services (AUL), worked to review, revise, and develop workflows and to test configurations in Alma and Leganto. The engagement team, created by a call for participants and comprised of three subject librarians and the AUL, worked to develop strategies, communications, and resources to promote and support the use of Leganto to instructors. Also, the two teams collaborated to test configurations and functions and suggest improvements. The AUL's presence in the teams was critically important to demonstrate senior leadership support of the project, an important element for success noted by O'Neill and Musto. ${ }^{20}$

Overall, this work required the teams to meet and discuss short-term and long-term changes to our course reserve service and how Leganto could be configured to support these. The rapid 
implementation schedule made this challenging because we had to start with the Leganto Now configurations and then test these to see how they aligned with our desired services and workflows. If they did not align well, we had to investigate and adapt. This was a back-and-forth negotiation as we learned in a short time frame how to configure the system to support our desired workflows and services and how to adjust our services and workflows to align with the capabilities/functionalities of the system.

An important part of the implementation was configuring Leganto to use the Learning Tools Interoperability (LTI) standard to integrate with D2L. As mentioned in the literature, having the online reading list solutions embedded and integrated with the institutional LMS is a key factor for successful adoption of the tool by instructors and students. ${ }^{21}$ Using the LTI integration, we were able to connect Alma, Leganto, and D2L. This work required coordination with the administrators of D2L at the University so that course and student data could be communicated between D2L, Alma, and Leganto. After configuring and testing the LTI integration, we decided to use it to create Reading List (Leganto) links in D2L courses through the D2L Tools menu. When a user clicks the link, user and course data from D2L is sent to Alma to

- create the course based on the course information and

- assign the appropriate role in Alma and Leganto for the instructor or student.

Since LCR could not provide physical reserves because of COVID-19, we decided to support the full/partial digitization of physical resources based on copyright approval and the creation of purchase requests for electronic copies of physical items added to a reading list. To achieve these goals, we needed to revise and establish workflows that make use of the basic digitization and purchase request functions in Leganto and Alma. These functions were not part of the Leganto Now configuration, but we decided to take the opportunity to make them available to instructors.

For our purposes, the digitization workflows and functions in Alma and Leganto would be used to support the full or partial scanning of physical resources. We already had workflows to support this type of work, but these needed to be revised so requests created by instructors in Leganto could be reviewed by the Copyright Office, items could be retrieved from the collection and scanned by staff, and scans could be made accessible in Leganto for instructors and students. The technical team worked with the departments involved in these workflows to determine how the new functions could support this work and how the workflows needed to be adjusted.

Also, we had to decide how to use the functions in Alma and Leganto to facilitate electronic purchase requests for print/physical resources added to readings lists. Similarly, we already had workflows for this but needed to review and revise these to make use of the functions supported by Alma and Leganto. Using these functions, we configured Alma and Leganto so that if an instructor added a book to their reading list and we did not have an e-book version, a purchase request for an e-book version would be submitted to the Collections department. This was achieved using tags and automatic processing rules with definable parameters.

There were a few other settings we had to customize to meet our needs. This included configuring the default out-of-the-box processing and copyright statuses for citations added to reading lists, reading list visibility settings to make sure only enrolled students could access the lists, user interface adjustments to control what functions are available to students and instructors, and interface text/messaging changes to align with our services. 
The other major part of this work involved engagement to publicize the new tool and provide training and support to instructors and library staff. The engagement team worked to develop resources and provided training to staff and instructors. Library staff were oriented to the product, the key benefits, and how to add course materials so that they could speak knowledgably to their faculty about the tool. Faculty training sessions introduced faculty to the tool and how to add specific types of resources, for example a book chapter, a website, or an item from their personal collection. One LibGuide was created to support both faculty and staff. Ex Libris provided support to the engagement team by providing communication templates and advice on engagement strategies. The team also promoted the new tool in our institutional newsletter and worked with the university's teaching and learning unit to promote it.

Overall, it was challenging during the five-week rapid implementation to quickly map and adapt our current course reserve workflows and ensure that these configurations will meet long term needs while considering the restraints of the current COVID environment.

\section{Go-live and Post go-live}

We finished implementation on June 29, 2020. For the summer term pilot, we only had one instructor publish a reading list for their course. However, instead of using the functionalities to add citations to the list the instructor uploaded a document version of their reading list. This was similar to what instructors were used to doing in D2L and we had to support the instructor to add the citations from the document to the reading list in Leganto. Shortly after going live, we had to make the LTI link to Leganto available in all courses because after publicizing the new tool, we received requests for access from instructors who were preparing for their fall term courses. This was sooner than expected and we believe this was because the online fall term may have motivated instructors to start preparing earlier than usual.

With the end of the fall 2020 term, we have been able to use Alma and Leganto's analytics reporting to see instructor use and student engagement with reading lists (see table 2). From these reports, we can see that for the fall 2020 term, there were 50 reading lists created that were associated with a course and that had at least one citation added. This means the instructors of these courses at least tried to use the reading list tool. However, of these 50 lists, there were only 30 lists that had student activity. Student activity is a category of interactions that Ex Libris uses to indicate how well the lists are being used by students and includes activities such as reading list views, number of citation views, number of full text views, number of files downloaded, and number of students that have marked a reading as done. We surmise that for the other 20 reading lists, the instructors encountered barriers to list creation and abandoned the process.

We continued to use the analytics reporting to monitor the status of instructor use for the winter 2021 term. By the end of that term, there were 66 lists created with at least one citation. 
Table 2. Fall 2020 and Winter 2021 Term usage

\begin{tabular}{|l|l|l|l|l|}
\hline Term & $\begin{array}{l}\text { Reading lists } \\
\text { with at least } \\
\text { one citation } \\
\text { added }\end{array}$ & $\begin{array}{l}\text { Number of } \\
\text { reading lists } \\
\text { with student } \\
\text { activity }\end{array}$ & $\begin{array}{l}\text { Students } \\
\text { viewing reading } \\
\text { lists }\end{array}$ & $\begin{array}{l}\text { Reading list } \\
\text { views }\end{array}$ \\
\hline Fall 2020 & 50 & 30 & 664 & 5,320 \\
\hline Winter 2021 & 66 & 49 & 1,154 & 13,200 \\
\hline
\end{tabular}

\section{TAKEAWAYS}

Rapidly implementing Leganto during COVID-19 has been a valuable and challenging learning experience which has offered several takeaways.

Go through rapid implementation with another university of a comparable size so that you can connect, support, and learn from each other. Rapid implementation is an intense period of uncertainty which can be challenging to go through alone. Another institution can provide support and help the implementation team cope. For example, during the implementation we had meetings with the University of Manitoba to discuss our progress and challenges with the implementation before meeting with the vendor implementation team. Since implementing we have stayed in contact and have been able to rely on each other to discuss the status of our engagement, adoption, and configurations.

Rapid implementation requires effort and time. The shortened implementation timeline implied that it would be relatively easy; however, the project dominated the schedules of those involved and has continued to require work. The weekly meetings with Ex Libris, the weekly internal meetings, the work in between meetings, and the continuous testing and reworking settings required a significant time commitment from all involved.

Timing is everything. We had hoped for a successful pilot in the summer term and to use this experience to learn and prepare for the wider rollout in the fall term. However, instructors began preparing for the fall term earlier than expected and consequently we needed to make Leganto accessible earlier. Understand your instructor timelines and practices around course preparation. The rapid implementation allowed us to respond to this unexpected pressure and begin to support instructors who wanted to make use of the tool.

Finally, further customizations and integrations will be necessary because of the nature of the rapid implementation and the inherent trade offs. The rapid implementation did not provide the time for us to pursue these customizations and integrations, and this is typical. For example, the course data integration would have required us to coordinate with our central IT department and Registrar to get approval and resources to build a data source and scripts to export and format the data so it could be loaded by the tool. Normal implementation would have provided support and time for this. Interestingly, Sheedy, Wells, and Bellenger in discussing their implementation at Curtin University noted that they too did not pursue some of the configurations during their implementation. ${ }^{22}$ Regardless of the implementation schedule, libraries maybe uncertain of how these configurations will be useful until after using the tool. 
In our case, it was after implementation that we realized the benefits these configurations could offer staff and users in terms of efficiency. Our next steps include

- loading course data (we are working on this with our central IT department and hope to have it complete for Summer 2021),

- refining and expanding the advanced automatic rules for copyright approval,

- refining digitization workflows, and

- implementing the Q\&A functionality to prompt faculty to describe if they need an entire ebook or just a digitized chapter.

These steps will support staff in the administration of courses and reading list in Alma and Leganto and in improved efficiency in processing citations. Furthermore, they will help ensure resources are accessible to all registered students for the appropriate time period.

\section{CONCLUSION}

It is not yet clear if the adoption of the tool has been successful with only 30 lists with student activity for the fall 2020 term and 49 for the winter 2021 term. We had hoped that given the increased need for online learning in this term, instructors would have been eager to use the reading list tool to support student access to resources and learning. Conversely, it seems likely that the new tool may have been too much for some instructors during this stressful period. ${ }^{23}$ Sheedy, Wells and Bellenger noted that there is a potential for system rejection by end users if the change is perceived as creating additional workloads for academic staff, and this may be a factor in our implementation. ${ }^{24}$ As a result, we will continue to monitor use and determine if our engagement strategies are working. If not, we will need to provide further engagement, training, and support to build interest and use.

The public health restrictions due to COVID-19 challenged the structure of learning and library services in post-secondary institutions. In some cases, these challenges were opportunities for change. Presented with the challenge of how to continue to provide course reserve reading list service, LCR decided to adopt Leganto through a rapid implementation. This implementation was an opportunity for LCR to continue to provide reserve reading list service while implementing new workflows to support online access to resources (digitization and purchase requests). Although this has met some of LCR's immediate needs, there is still work that needs to be done to ensure long term successful adoption and use. We will need to continue to review and improve engagement strategies, workflows, and integrations to make the most of this investment.

\section{ENDNOTES}

${ }^{1}$ Gary Brewerton and Jon Knight, "From Local Project to Open Source: A Brief History of the Loughborough Online Reading List System (LORLS),” Vine 33, no. 4 (2003): 189-95, https://doi.org/10.1108/03055720310510909.

2 Richard Cross, "Implementing a Resource List Management System in an Academic Library," Electronic Library 33, no. 2 (July 2015): 221, https://doi.org/10.1108/el-05-2013-0088.

3 “Leganto Course Resource List Management,” Ex Libris, March 18, 2021, https://exlibrisgroup.com/products/leganto-reading-list-management-system/. 
${ }^{4}$ Cross, "Implementing a Resource List Management System;" Brewerton and Knight, "Local Project to Open Source.”

${ }^{5}$ Marie O'Neill and Lara Musto, "Faculty Perceptions of Loughborough's Online Reading List System (LORLS) at Dublin Business School (DBS)," New Review of Academic Librarianship 23, no. 4 (2016): 368, https://doi.org/10.1080/13614533.2016.1272473; Cross, "Implementing a Resource List Management System in an Academic Library."

${ }^{6}$ Cross, "Implementing a Resource List Management System”; Brewerton and Knight, "Local Project to Open Source"; O’Neill and Musto, "Faculty Perceptions"; Olivia Walsby, "Implementing a Reading List Strategy at The University of Manchester-Determination, Collaboration and Innovation," Insights the UKSG Journal 33

(2020), https://doi.org/10.1629/uksg.494.

${ }^{7}$ 0’Neill and Musto, “Faculty Perceptions," 368.

${ }^{8}$ 0’Neill and Musto, "Faculty Perceptions," 368.

${ }^{9}$ O’Neill and Musto, "Faculty Perceptions," 368; Linda Sheedy, David Wells, and Amanda Bellenger, "Implementation of a Leganto Reading List Service at Curtin University Library," in Technology, Change and the Academic Library, ed. Jeremy Atkinson (Chandos Publishing, 2021), 5561, https://doi.org/10.1016/B978-0-12-822807-4.00005-1.

10 O’Neill and Musto, "Faculty Perceptions," 368.

${ }^{11}$ Walsby, "Implementing a Reading List Strategy."

12 O’Neill and Musto, "Faculty Perceptions," 368.

13 Meredith Gorran Farkas, "Libraries in the Learning Management System," in American Libraries Tips and Trends (Summer 2015), https://acrl.ala.org/IS/wpcontent/uploads/2014/05/summer2015.pdf.

14 Jennifer Murray and Daniel Feinberg, “Collaboration and Integration,” Information Technology and Libraries 39, no. 2 (November 2020), https://doi.org/10.6017/ital.v39i2.11863.

${ }^{15}$ Murray and Feinberg, “Collaboration and Integration,” 9.

16 O’Neill and Musto, "Faculty Perceptions," 368.

17 Cross, "Implementing a Resource List Management System."

${ }^{18}$ Ex Libris, “Course Materials Affordability: A Win for University of St. Thomas," Library Journal (November 7, 2018), https://www.libraryjournal.com/?detailStory=course-materialsaffordability-a-win-for-university-of-st-thomas.

19 “Canada's Best Medical Doctoral Universities: Rankings 2020,” Maclean’s, October 3, 2019, https://www.macleans.ca/education/university-rankings-2020-canadas-top-medicaldoctoral-schools/. 
${ }^{20}$ O’Neill and Musto, "Faculty Perceptions," 368.

${ }^{21}$ Murray and Feinberg, "Collaboration and Integration," 9.

${ }^{22}$ Sheedy, Wells, and Bellenger, “Implementation of a Leganto Reading List Service," 55-61.

23 "Faculty Wellness and Careers," Course Hero (blog), December 1, 2020, https://www.coursehero.com/blog/faculty-wellness-research/.

${ }^{24}$ Sheedy, Wells, and Bellenger, “Implementation of a Leganto Reading List Service,” 55-61. 